\title{
No-touch methods of terminal cleaning in the intensive care unit: results from the first large randomized trial with patient-centred outcomes
}

\author{
Vincenzo Russotto ${ }^{1 *}$ D, Andrea Cortegiani ${ }^{1}$, Pasquale lozzo $^{2}$, Santi Maurizio Raineri ${ }^{1}$, Cesare Gregoretti ${ }^{1}$
} and Antonino Giarratano ${ }^{1}$

Keywords: Terminal cleaning, Sepsis, ICU-acquired infections, Multidrug resistant organisms

Environmental contamination may play a major role in intensive care unit (ICU)-acquired infections, despite current terminal cleaning standards [1]. Anderson et al. [2] recently performed the first large randomized trial investigating a no-touch method of terminal cleaning with a patient-centred outcome, and provided more robust data on the role of environmental contamination for healthcare-associated infections. The authors evaluated three different enhanced terminal disinfection methods (ultraviolet, UV light, UV light plus bleach, and bleach) compared to the reference standard for prevention of transmission of multidrug resistant organisms (MDROs) and Clostridium difficile to patients exposed to a room whose prior occupant was either colonized or infected with a MDRO.

The addition of UV light to the reference disinfection strategy (based on quaternary ammonium) reduced the transmission of the targeted MDROs (methicillin-resistant Staphylococcus aureus and vancomycin-resistant enterococci) by $30 \%$, while no significant difference was observed when UV light was compared to bleach or to the combination of bleach and UV. Moreover, the authors did not observe a difference in colonization and infection by $C$. difficile when UV light was added to bleach (the standard disinfection method for C. difficile). We agree with them that this would represent the minimum effect of the UV strategy and that, in a real-life

\footnotetext{
* Correspondence: vinrussotto@gmail.com

${ }^{1}$ Department of Biopathology and Medical Biotechnologies (DIBIMED), Section of Anesthesia Analgesia Intensive Care and Emergency. Policlinico P. Giaccone, University of Palermo, Via del Vespro 129, 90127 Palermo, Italy Full list of author information is available at the end of the article
}

scenario with considerably less cleaning compliance, the benefit from UV-based enhanced terminal cleaning would have been more incisive. Notably, killing of C. difficile spores appeared to be time- and dosedependent in a previously published study [3].

ICU-acquired infections are a major health problem worldwide [4]. Environmental contamination may pose an even higher challenge in this setting due to a number of factors: a higher prevalence of colonization and infection by MDROs, understaffing, the presence of sophisticated equipment with high-touch surfaces and specific cleaning procedures [1]. The benefit of no-touch methods for terminal cleaning may be theoretically higher in these circumstances. Unfortunately, the study did not provide data on Acinetobacter since only one exposed patient acquired this organism. The role of Gram-negative bacteria may be more relevant in the ICUs. In a meta-analysis of studies investigating the risk of acquiring bacteria from prior bed occupants, the odds ratio for acquisition of Acinetobacter was the highest, corresponding to 4.91 (95\% CI 2.79-8.64) [5]. The study by Anderson et al. highlights how terminal cleaning may be considered the basis to build an effective strategy to reduce healthcare-associated infections.

\section{Abbreviations}

ICU: Intensive care unit; MDRO: Multidrug resistant organism; UV: Ultraviolet
Acknowledgements

None.

Funding

The authors did not receive any funding for this article. 


\section{Availability of data and materials}

Not applicable.

\section{Authors' contributions}

VR, AC, PI, SMR, CG, and AG conceived the content of the letter. VR and AC wrote the text. All authors read and approved the final version of the manuscript.

\section{Competing interests}

The authors declare that they have no competing interests.

\section{Consent for publication}

Not applicable.

Ethics approval and consent to participate

Not applicable.

\section{Publisher's Note}

Springer Nature remains neutral with regard to jurisdictional claims in published maps and institutional affiliations.

\section{Author details}

'Department of Biopathology and Medical Biotechnologies (DIBIMED), Section of Anesthesia Analgesia Intensive Care and Emergency. Policlinico P. Giaccone, University of Palermo, Via del Vespro 129, 90127 Palermo, Italy. ${ }^{2}$ Intensive Care Unit, Policlinico Paolo Giaccone, University of Palermo, Via del Vespro 129, 90127 Palermo, Italy.

Published online: 30 July 2017

\section{References}

1. Russotto V, Cortegiani A, Raineri SM, Giarratano A. Bacterial contamination of inanimate surfaces and equipment in the intensive care unit. J Intensive Care. 2015;3:54.

2. Anderson DJ, Chen LF, Weber DJ, Moehring RW, Lewis SS, Triplett PF, Blocker M, Becherer P, Schwab JC, Knelson LP, et al. Enhanced terminal room disinfection and acquisition and infection caused by multidrugresistant organisms and Clostridium difficile (the Benefits of Enhanced Terminal Room Disinfection study): a cluster-randomised, multicentre, crossover study. Lancet (London, England). 2017;389(10071):805-14.

3. Nerandzic MM, Cadnum JL, Pultz MJ, Donskey CJ. Evaluation of an automated ultraviolet radiation device for decontamination of Clostridium difficile and other healthcare-associated pathogens in hospital rooms. BMC Infect Dis. 2010;10:197.

4. Cortegiani A, Russotto V, Graziano G, Geraci D, Saporito L, Cocorullo G, Raineri SM, Mammina C, Giarratano A. Use of Cepheid Xpert Carba-R(R) for rapid detection of carbapenemase-producing bacteria in abdominal septic patients admitted to intensive care unit. PLoS One. 2016;11(8):e0160643.

5. Russotto V, Cortegiani A, Raineri SM, lozzo P, Gregoretti C, Giarratano A. What is the risk of acquiring bacteria from prior intensive care unit bed occupants? Crit Care. 2017;21(1):55. 